\title{
Monitoring and control of stored grain insect pests in grain stores in Poland
}

\section{Monitoring i zwalczanie szkodników w obiektach magazynowych w Polsce}

\author{
Paweł Olejarski ${ }^{1}$, Paweł Węgorek ${ }^{2}$, Joanna Zamojska
}

\section{Summary}

Grain storage conditions and the occurrence of the grain storage pests plays a major role in the reduce losses and maintaining the high value of stored material. In order to know the conditions of storage of cereals and the occurrence of storage pests in them and pests control a detailed survey was sent to the entities responsible for grain storage facilities in Poland. The paper presents the results of a survey collected from 49 locations in the area of 11 out of 16 voivodeships covered by the survey research. The survey included questions about storage time of grain, measuring and control devices installed in granaries conducted monitoring of storage pests, the most common pests occurrence in storage grain, term treatments for pest control and used of plant protection product.

Key words: storage conditions, storage pest, monitoring, control, insecticides

\section{Streszczenie}

Warunki magazynowania zbóż i ewentualna obecność w nich szkodników magazynowych w znacznej mierze wpływa na ostateczny poziom strat i jakość składowanego surowca. W celu poznania warunków składowania zbóż, występujących w nich szkodników i prowadzonego zwalczania opracowano szczegółową ankietę, którą rozsyłano wśród podmiotów zajmujących się magazynowaniem zbóż na terenie Polski. Praca przedstawia wyniki ankiety zebranej z 49 lokalizacji, z obszaru 11 z 16 objętych badaniami ankietowymi województw. Przeprowadzona ankieta zawierała pytania odnośnie czasu przechowywania zbóż, wyposażenia magazynów w urządzenia pomiarowo-kontrolne, prowadzonego monitoringu obecności szkodników magazynowych, najczęściej występujących szkodników magazynowych, terminu przeprowadzania zabiegów zwalczania szkodników i stosowanych środków.

Słowa kluczowe: warunki magazynowania, szkodniki magazynowe, monitoring, zwalczanie, insektycydy

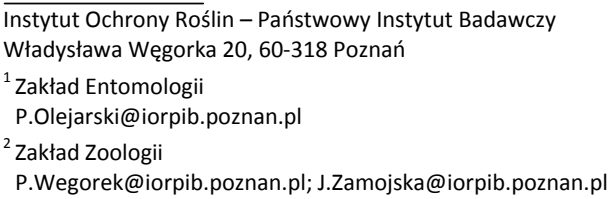




\section{Wstęp / Introduction}

Pojęcie szkodników magazynowych związane jest z magazynowanymi surowcami, w tym w sposób szczególny z ziarnem zbóż i wieloma gotowymi produktami. Szacuje się, że w magazynach może występować nawet kilkaset różnych gatunków organizmów żywych (Rajendran 2002).

Ziarno zbóż jest głównym źródłem pożywienia dla ludzi, ważnym i wartościowym składnikiem pasz oraz cennym surowcem dla przemysłu. Ze względu na swe walory odżywcze jest także atrakcyjnym pożywieniem dla wielu szkodników magazynowych, głównie roztoczy i owadów. Zjadając zmagazynowane zboża powodują one straty bezpośrednie, ale szkodzą także pośrednio zanieczyszczając je, co prowadzi do pogorszenia wartości siewnej, odżywczej i technologicznej surowca (Gołębiowska i wsp. 1968). Część zanieczyszczeń może przedostawać się do produkowanej żywności i po jej spożyciu powodować u konsumentów różne stany chorobowe, głównie reakcje alergiczne (Phillips i Burkholder 1984; Stejskal i Hubert 2006; Sadowski i Drobek 2007).

Zebranego ziarna zbóż nie da się od razu zagospodarować. Znaczna część jest magazynowana na późniejsze wykorzystanie, a także na wypadek nieurodzaju, klęski żywiołowej czy innych niekorzystnych zdarzeń (Neethirajan i wsp. 2007).

Biorąc po uwagę znaczenie zbóż dla człowieka i straty, jakie mogą powodować szkodniki je zasiedlające, istotne znaczenie odgrywają warunki magazynowania tego surowca, prowadzony monitoring występowania szkodników i właściwe zwalczanie. Zasobność portfela oraz świadomość osób zajmujących się magazynowaniem zbóż odgrywa decydujące znaczenie dla bezpieczeństwa zmagazynowanych zbóż i wytwarzanej $\mathrm{z}$ nich później żywności. W ustawodawstwie Europejskim wyraźnie wskazano, że „W celu zapewnienia bezpieczeństwa żywności, konieczne jest uwzględnienie wszystkich aspektów łańcucha produkcji żywności począwszy od produkcji podstawowej i produkcji pasz, aż do sprzedaży lub dostawy żywności do konsumenta, ponieważ każdy element może mieć potencjalny wpływ na bezpieczeństwo żywności" (Rozporządzenie 178 WE 2002).

W celu poznania warunków, w jakich przechowywane jest ziarno zbóż w Polsce oraz czy i jak prowadzony jest monitoring i zwalczanie szkodników magazynowych, w Instytucie Ochrony Roślin - Państwowym Instytucie Badawczym w Poznaniu, w Zakładzie Entomologii opracowano specjalną ankietę.

\section{Materiały i metody / Materials and methods}

Pytania zawarte w ankiecie dotyczyły rodzaju magazynów, warunków składowania i rodzaju oraz ilości przechowywanych surowców, czasu magazynowania, wyposażenia obiektów w urządzenia pomiarowo-kontrolne (czujniki temperatury i wilgotności), prowadzonego monitoringu obecności szkodników, występujących na składowanym surowcu szkodników oraz prowadzonego zwalczania i stosowanych pestycydów.
Na potrzeby prowadzonych badań ankietowych z Wojewódzkich Inspektoratów Ochrony Roślin i Nasiennictwa, z Głównego Inspektoratu Jakości Handlowej Artykułów Rolno-Spożywczych oraz z Agencji Rynku Rolnego otrzymano adresy podmiotów magazynujących ziarno zbóż na terenie całego kraju. W latach 2011 i 2012 opracowana ankietę rozsyłano do rolników indywidualnych magazynujących ziarno zbóż na małą skalę, jak również do właścicieli dużych, profesjonalnych silosów zbożowych, a także do innych podmiotów zajmujących się obrotem mniejszych lub większych ilości ziarna. Ponadto ankiety zbierano także w trakcie lustracji terenowych prowadzonych w magazynach zbożowych. We wszystkich przypadkach ankietowani mogli wypełniać ankiety anonimowo lub jeśli chcieli, podawać swoje dane teleadresowe.

\section{Wyniki i dyskusja / Results and discussion}

W sumie ankiety zebrano z 49 lokalizacji, z obszaru $11 \mathrm{z} 16$ objętych badaniami województw. Były to województwa: dolnośląskie, kujawsko-pomorskie, lubuskie, małopolskie, mazowieckie, opolskie, podkarpackie, pomorskie, śląskie, wielkopolskie i zachodnio-pomorskie.

Najwięcej, bo aż 16 ankiet zebrano z województwa wielkopolskiego. Z województwa lubuskiego i dolnośląskiego nieco mniej, odpowiednio 7 i 6 ankiet. Najmniej ankiet, bo tylko po jednej zebrano $\mathrm{z}$ województwa mazowieckiego, podkarpackiego i zachodnio-pomorskiego. Syntetyczne wyniki ankietowe zestawiono w tabeli 1. i 2.

Ziarno zbóż w Polsce przechowywane jest w bardzo różnych obiektach, zarówno pod względem „wieku”, wielkości (pojemności magazynowej), jak i konstrukcji. Na podstawie ankiety ustalono, że ziarno przechowywane jest zarówno w magazynach płaskich, jak i silosowych. Magazyny silosowe w większości ankietowanych przypadków były o konstrukcji stalowej. Silosy o konstrukcji betonowej stwierdzono w kilku lokalizacjach, w których składowano bardzo duże ilości ziarna, zwykle ponad kilkadziesiąt tysięcy ton i przez długi okres czasu - ponad 2 lata.

W objętych ankietą magazynach przechowywane było głównie ziarno różnych gatunków zbóż (pszenica, pszenżyto, jęczmień, owies, kukurydza i inne). W niektórych przypadkach ziarno zbóż magazynowane było przemiennie $\mathrm{z}$ nasionami rzepaku i roślin strączkowych. Problem szkodników magazynowych nie dotyczy tylko zbóż, ale także obiektów, w których magazynuje się nasiona rzepaku, o czym donoszą liczne obserwacje zagraniczne (Sinha 1972; Sinha i Wallace 1977; Loschiavo i Lamba 1985). Także w warunkach Polski zaobserwowano już występowanie niektórych gatunków szkodników magazynowych na magazynowanym rzepaku (Olejarski 2011; Olejarski i Rybacki 2011).

Średni czas przechowywania ziarna w większości poddanych badaniom ankietowym magazynów wynosił od 6 do 12 miesięcy. W nielicznych, profesjonalnych obiektach, gdzie magazynowano bardzo duże ilości ziarna czas ten był dłuższy i wynosił do 24, a nawet do 36 miesięcy. $\mathrm{Na}$ podstawie przeprowadzonej ankiety stwierdzono, że tylko w około $1 / 5$ obiektów magazynowych (w 12 na 
49 badanych) zainstalowane były jakiekolwiek urządzenia pomiarowo-kontrolne mierzące na bieżąco temperaturę, bądź temperaturę i wilgotność składowanych zbóż. W wielu przypadkach ankietowani donosili tylko o okresowym, manualnym wykonywaniu pomiaru temperatury, czy wilgotności składowanych zbóż. Wykonywano to najczęściej pobierając sondą próbki ziarna do badań lub w trakcie jego przesypywania. Fakt ten jest niezwykle niepokojący, ponieważ warunki przechowywanych zbóż powinny być pod stałą kontrolą. Nie można bowiem bezpiecznie przechować surowca w warunkach zbyt wysokiej temperatury i wilgotności, które sprzyjają rozwojowi nie tylko szkodników, ale także mikroflory bakteryjno-grzybowej. W prowadzonych wcześniej badaniach ankietowych dotyczących magazynowania nasion rzepaku w Polsce stwierdzono, że obiekty te prawdopodobnie ze względu na specyficzne wymagania surowca (łatwo i w krótkim czasie psuje się) i wysokie wymagania stawiane przez podmioty skupujące praktycznie wszystkie były wyposażone w urządzenia pomiarowo-kontrolne (Olejarski i Rybacki 2011).

Nieco lepiej przedstawiała się sytuacja odnośnie prowadzenia monitoringu występowania szkodników magazynowych. Na podstawie ankiet stwierdzono, że w 40 na 49 lokalizacjach prowadzony był taki monitoring. Polegał on głównie na wzrokowej obserwacji pryzmy ziarna lub przesiewaniu pobranych próbek ziarna na obecność szkodników i śladów ich żerowania. Jednakże stosowanie praktycznie tylko jednej $\mathrm{z}$ wielu dostępnych metod wykrywania szkodników magazynowych (Rajendran 2005) uniemożliwia wczesne wykrycie szkodników i tym samym zminimalizowanie strat do możliwego minimum.

Tabela 1. Wyniki ankiety przeprowadzonej wśród podmiotów magazynujących ziarno zbóż w latach 2007-2011 (warunki magazynowania)

Table 1. The results of a survey conducted among entities responsible for cereal grain storage in the years 2007 to 2011 (storage conditions)

\begin{tabular}{|c|c|c|c|c|c|}
\hline $\begin{array}{l}\text { Lp. } \\
\text { No. }\end{array}$ & $\begin{array}{l}\text { Województwo } \\
\text { Voivodeship }\end{array}$ & $\begin{array}{c}\text { Liczba miejscowości/ } \\
\text { lokalizacji, w których } \\
\text { przeprowadzono ankiete } \\
\text { Number of locations }\end{array}$ & $\begin{array}{c}\text { Czas przechowywania } \\
\text { surowca w magazynie } \\
\text { [średnio, w miesiącach] } \\
\text { Storage time } \\
\text { [average, in month] }\end{array}$ & $\begin{array}{c}\text { Zainstalowane urządzenia } \\
\text { pomiarowo-kontrolne } \\
\text { Installed measuring } \\
\text { and control systems } \\
{[\mathrm{X} / \mathrm{Y}]} \\
{[\mathrm{T} \text { - czujnik temperatury }} \\
\mathrm{H} \text { - czujnik wilgotności }] \\
{[\mathrm{T}-\text { temperature sensor }} \\
\mathrm{H} \text { - humidity sensor }]\end{array}$ & $\begin{array}{c}\text { Prowadzony } \\
\text { monitoring } \\
\text { szkodników } \\
\text { (obserwacja } \\
\text { wzrokowa) } \\
\text { Conducted } \\
\text { monitoring of pests } \\
\text { (visual observation) } \\
{[\mathrm{X} / \mathrm{Y}]}\end{array}$ \\
\hline 1. & dolnośląskie & 6 & $6-12$ & $\begin{array}{c}3 / 6 \\
(2 / 6 \mathrm{~T}) \\
(1 / 6 \mathrm{~T}+\mathrm{H}) \\
\end{array}$ & $4 / 6$ \\
\hline 2. & kujawsko-pomorskie & 3 & $6-12$ & $0 / 3$ & $3 / 3$ \\
\hline 3. & lubuskie & 7 & $6-12$ & $\begin{array}{c}1 / 7 \\
(1 / 7 \mathrm{~T}) \\
\end{array}$ & $6 / 7$ \\
\hline 4. & małopolskie & 2 & $8-12$ & $\begin{array}{c}1 / 2 \\
(1 / 2 \mathrm{~T})\end{array}$ & $2 / 2$ \\
\hline 5. & mazowieckie & 1 & $\begin{array}{c}\text { do } 6 \\
\text { up to } 6\end{array}$ & $0 / 1$ & $1 / 1$ \\
\hline 6. & opolskie & 2 & $3-10$ & $\begin{array}{c}1 / 2 \\
(1 / 2 \mathrm{~T}) \\
\end{array}$ & $2 / 2$ \\
\hline 7. & podkarpackie & 1 & $\begin{array}{c}\text { do } 6 \\
\text { up to } 6\end{array}$ & $0 / 1$ & $0 / 1$ \\
\hline 8. & pomorskie & 5 & $\begin{array}{c}6-12 \\
\text { (lokalnie do 24) } \\
\text { (locally up to 24) } \\
\end{array}$ & $\begin{array}{c}2 / 5 \\
(1 / 4 \mathrm{~T}) \\
(1 / 4 \mathrm{~T}+\mathrm{H}) \\
\end{array}$ & $5 / 5$ \\
\hline 9. & śląskie & 5 & $3-12$ & $0 / 5$ & $2 / 5$ \\
\hline 10. & wielkopolskie & 16 & $\begin{array}{c}6-12 \\
\text { (lokalnie do 36) } \\
\text { (locally up to 36) }\end{array}$ & $\begin{array}{c}4 / 16 \\
(2 / 16 \mathrm{~T}) \\
(2 / 16 \mathrm{~T}+\mathrm{H}) \\
\end{array}$ & $15 / 16$ \\
\hline 11. & zachodnio-pomorskie & 1 & $1-10$ & $0 / 1$ & $0 / 1$ \\
\hline
\end{tabular}

$\mathrm{X}$ - liczba lokalizacji, w których badany czynnik zastosowano/obserwowano - number of locations where tested factor occure $\mathrm{Y}$ - całkowita liczba ankiet zebranych w danym województwie - total number of surveys collected in the region 
Tabela 2. Wyniki ankiety przeprowadzonej wśród podmiotów magazynujących ziarno zbóż w latach 2007-2011 (szkodniki i zwalczanie)

Table 2. The results of a survey conducted among entities responsible cereal grain storage in the years 2007 to 2011 (pests and pest control)

\begin{tabular}{|c|c|c|c|c|c|c|c|}
\hline \multirow[b]{2}{*}{$\begin{array}{l}\text { Lp. } \\
\text { No. }\end{array}$} & \multirow[b]{2}{*}{$\begin{array}{l}\text { Województwo } \\
\text { Voivodeship }\end{array}$} & \multirow[b]{2}{*}{$\begin{array}{c}\text { Stwierdzane szkodniki } \\
\text { Stored pest detected } \\
{[\mathrm{X} / \mathrm{Y}]}\end{array}$} & \multirow[b]{2}{*}{$\begin{array}{l}\text { Termin wykonania } \\
\text { zabiegów zwalczania } \\
\text { szkodników } \\
\text { Date } \\
\text { of treatments } \\
\text { for pest control }\end{array}$} & \multicolumn{4}{|c|}{$\begin{array}{l}\text { Zabiegi zwalczania szkodników } \\
\text { Pest control }\end{array}$} \\
\hline & & & & $\begin{array}{c}\text { we własnym } \\
\text { zakresie } \\
\text { by oneself } \\
{[\mathrm{X} / \mathrm{Y}]}\end{array}$ & $\begin{array}{c}\text { zewnętrzna } \\
\text { firma DDD } \\
\text { external } \\
\text { company } \\
{[\mathrm{X} / \mathrm{Y}]}\end{array}$ & $\begin{array}{l}\text { substancja } \\
\text { czynna } \\
\text { active } \\
\text { substance } \\
{[\mathrm{X} / \mathrm{Y}]}\end{array}$ & $\begin{array}{c}\text { środki } \\
\text { biobójcze } \\
\text { stosowane } \\
\text { w pustym } \\
\text { magazynie } \\
\text { biocides } \\
\text { used in empty } \\
\text { stores } \\
{[\mathrm{X} / \mathrm{Y}]} \\
\end{array}$ \\
\hline 1 & 2 & 3 & 4 & 5 & 6 & 7 & 8 \\
\hline 1. & dolnośląskie & $\begin{array}{l}\text { Stophilus granarius }(4 / 6), \\
\text { Tribolium spp. }(3 / 6), \\
\text { Plodia interpunctella }(1 / 6), \\
\text { Acarina }(3 / 6)\end{array}$ & $\begin{array}{l}\text { przed żniwami, } \\
\text { interwencyjnie } \\
\text { before harvest, } \\
\text { an intervention }\end{array}$ & $4 / 6$ & $4 / 6$ & $\begin{array}{c}4 / 6- \\
\text { pirimiphos- } \\
\text { methyl } \\
2 / 6- \\
\text { deltamethrin } \\
4 / 6- \\
\text { phosphine }\end{array}$ & $2 / 6$ \\
\hline 2. & $\begin{array}{l}\text { kujawsko- } \\
\text { pomorskie }\end{array}$ & $\begin{array}{l}\text { Sitophilus granaries }(2 / 3), \\
\text { S. zea-mays }(1 / 3), \\
\text { Tribolium spp. }(1 / 3), \\
\text { Cryptolestes spp. }(1 / 3), \\
\text { Tenebrio molitor }(1 / 3), \\
\text { Alphitobius bifasciatus }(1 / 3), \\
\text { Typhea stercorea }(2 / 3), \\
\text { Anthicus floralis }(1 / 3), \\
\text { Anagasta kühniella }(1 / 3)\end{array}$ & $\begin{array}{l}\text { przed żniwami, } \\
\text { interwencyjnie } \\
\text { before harvest, } \\
\text { an intervention }\end{array}$ & $2 / 3$ & $3 / 3$ & $\begin{array}{l}2 / 3- \\
\text { pirimiphos- } \\
\text { methyl }\end{array}$ & $3 / 3$ \\
\hline 3. & lubuskie & $\begin{array}{l}\text { Sitophilus spp. }(5 / 7), \\
\text { Tribolium spp. }(5 / 7), \\
\text { Sitotroga cerealella }(1 / 7), \\
\text { Anagasta kühniella }(1 / 7), \\
\text { Acarina }(2 / 7)\end{array}$ & $\begin{array}{l}\text { przed żniwami, } \\
\text { interwencyjnie } \\
\text { before harvest, } \\
\text { an intervention }\end{array}$ & $5 / 7$ & $2 / 7$ & $\begin{array}{c}5 / 7- \\
\text { pirimiphos- } \\
\text { methyl } \\
1 / 7- \\
\text { deltamethrin } \\
3 / 7- \\
\text { phosphine }\end{array}$ & $3 / 7$ \\
\hline 4. & małopolskie & Tribolium spp. (1/2) & $\begin{array}{l}\text { przed żniwami, } \\
\text { interwencyjnie } \\
\text { before harvest, } \\
\text { an intervention }\end{array}$ & $1 / 2$ & $1 / 2$ & $\begin{array}{l}2 / 2- \\
\text { pirimiphos- } \\
\text { methyl }\end{array}$ & $1 / 2$ \\
\hline 5. & mazowieckie & $\begin{array}{l}\text { brak danych } \\
\text { no data }\end{array}$ & $\begin{array}{l}\text { przed żniwami, } \\
\text { interwencyjnie } \\
\text { before harvest, } \\
\text { an intervention }\end{array}$ & $1 / 1$ & $0 / 1$ & $\begin{array}{l}1 / 1- \\
\text { pirimiphos- } \\
\text { methyl }\end{array}$ & $0 / 1$ \\
\hline 6. & opolskie & $\begin{array}{l}\text { Sitophilus spp. }(2 / 2), \\
\text { Tribolium } \text { spp. }(2 / 2), \\
\text { Cryptolestes } \text { spp. }(1 / 2), \\
\text { Rhizopertha dominica }(1 / 2), \\
\text { Acarina }(1 / 2)\end{array}$ & $\begin{array}{l}\text { przed żniwami, } \\
\text { interwencyjnie } \\
\text { before harvest, } \\
\text { an intervention }\end{array}$ & $0 / 2$ & $2 / 2$ & $\begin{array}{c}1 / 1- \\
\text { pirimiphos- } \\
\text { methyl } \\
1 / 1- \\
\text { phosphine }\end{array}$ & $0 / 2$ \\
\hline 7. & podkarpackie & Anagasta kühniella $(1 / 1)$ & $\begin{array}{l}\text { przed żniwami, } \\
\text { interwencyjnie } \\
\text { before harvest, } \\
\text { an intervention }\end{array}$ & $0 / 1$ & $1 / 1$ & $\begin{array}{c}1 / 1- \\
\text { pirimiphos- } \\
\text { methyl } \\
1 / 1- \\
\text { phosphine }\end{array}$ & $1 / 1$ \\
\hline 8. & pomorskie & $\begin{array}{l}\text { Sitophilus spp. }(2 / 5), \\
\text { Tribolium spp. }(3 / 5), \\
\text { Cryptolestes spp. }(1 / 5), \\
\text { Acarina }(1 / 5)\end{array}$ & $\begin{array}{l}\text { przed żniwami, } \\
\text { interwencyjnie } \\
\text { before harvest, } \\
\text { an intervention }\end{array}$ & $2 / 5$ & $4 / 5$ & $\begin{array}{c}4 / 5- \\
\text { pirimiphos- } \\
\text { methyl } \\
5 / 5- \\
\text { phosphine }\end{array}$ & $2 / 5$ \\
\hline
\end{tabular}




\begin{tabular}{|c|c|c|c|c|c|c|c|}
\hline 1 & 2 & 3 & 4 & 5 & 6 & 7 & 8 \\
\hline 9. & śląskie & $\begin{array}{l}\text { Sitophilus spp. }(2 / 5), \\
\text { Tribolium spp. }(3 / 5), \\
\text { Anagasta kühniella }(2 / 5), \\
\text { Acarina }(1 / 5)\end{array}$ & $\begin{array}{l}\text { przed żniwami, } \\
\text { interwencyjnie } \\
\text { before harvest, } \\
\text { an intervention }\end{array}$ & $3 / 5$ & $4 / 5$ & $\begin{array}{l}4 / 5- \\
\text { pirimiphos- } \\
\text { methyl } \\
3 / 5- \\
\text { phosphine }\end{array}$ & $1 / 5$ \\
\hline 10. & wielkopolskie & $\begin{array}{l}\text { Sitophilus granarius }(7 / 16) \text {, } \\
\text { Tribolium spp. }(6 / 16), \\
\text { Tenebrio molitor }(1 / 16), \\
\text { Psocoptera }(2 / 16), \\
\text { Anagasta kühniella }(4 / 16), \\
\text { Acarina }(5 / 16)\end{array}$ & $\begin{array}{l}\text { przed żniwami, } \\
\text { interwencyjnie } \\
\text { before harvest, } \\
\text { an intervention }\end{array}$ & $7 / 16$ & $10 / 16$ & $\begin{array}{l}8 / 16- \\
\text { pirimiphos- } \\
\text { methyl } \\
8 / 16- \\
\text { phosphine }\end{array}$ & $5 / 16$ \\
\hline 11. & $\begin{array}{l}\text { zachodnio- } \\
\text { pomorskie }\end{array}$ & $\begin{array}{l}\text { brak danych } \\
\text { no data }\end{array}$ & $\begin{array}{l}\text { nie zwalcza się } \\
\text { no pest control }\end{array}$ & $\begin{array}{c}0 / 1 \\
\text { nie są } \\
\text { prowadzone } \\
\text { are } \\
\text { not carried } \\
\text { out }\end{array}$ & $\begin{array}{c}0 / 1 \\
\text { nie są } \\
\text { prowadzone } \\
\text { are } \\
\text { not carried } \\
\text { out }\end{array}$ & $\begin{array}{c}0 / 1 \\
\text { nie są } \\
\text { stosowane } \\
\text { not used }\end{array}$ & $\begin{array}{c}0 / 1 \\
\text { nie są } \\
\text { stosowane } \\
\text { not used }\end{array}$ \\
\hline
\end{tabular}

$\mathrm{X}$ - liczba lokalizacji, w których badany czynnik zastosowano/obserwowano - number of locations where tested factor occure Y - całkowita liczba ankiet zebranych w danym województwie - total number of surveys collected in the region

Tylko w 5 na 49 ankiet podano informacje na temat stosowanych urządzeń monitorujących obecność szkodników magazynowych. W 4 przypadkach ankietowani donosili o stosowaniu detektorów/pułapek feromonowych na motyle magazynowe i w jednym przypadku o stosowaniu karmników deratyzacyjnych. Jest to zdecydowanie za mało zważywszy, że już od 1 stycznia 2014 r. rolników obowiązywać będą zasady integrowanej ochrony roślin (Dyrektywa 128 WE 2009; Rozporządzenie 1107 WE 2009).

W większości przypadków ankietowani podali, że zwalczanie szkodników prowadzone było w okresie poprzedzającym okres magazynowania $\mathrm{i}$ interwencyjnie po stwierdzeniu obecności szkodników w surowcu.

W przypadku stosowania środków kontaktowych i w mniejszych obiektach magazynowych, zabiegi zwalczania szkodników wykonywane były zwykle we własnym zakresie. Zabiegi zwalczania przez zewnętrzną firmę DDD (dezynfekcja, dezynsekcja, deratyzacja) wykonywane były zwykle w dużych, profesjonalnych obiektach magazynowych i w przypadku stosowania bardzo toksycznych środków fosforowodorowych. Stosowanie fumigantów wymaga bowiem ukończenia specjalistycznego szkolenia (Ustawa o ochronie roślin 2008), odpowiedniego przygotowania surowca (dosuszenie, wzruszenie zleżałego surowca w celu lepszej penetracji gazu) i obiektu do gazowania (dobre doszczelnienie, stosowanie gazoszczelnej folii i pianki, itp.), a w trakcie samego zabiegu stosowania odpowiedniego wyposażenia do kontrolowania parametrów (rurki wskaźnikowe do pomiaru stężeń $\mathrm{PH}_{3}$, wskaźniki elektroniczne). Niezmiernie istotne jest stosowanie środków ochrony osobistej (maski przeciwgazowe z pochłaniaczami na $\mathrm{PH}_{3}$, osobiste detektory $\mathrm{PH}_{3}$, itp.). Część ankietowanych wskazywała, że wykonuje zabiegi fumigacji we własnym zakresie, zatem należy uznać, że są to osoby legitymujące się odpowiednim i ważnym zaświadczeniem potwierdzającym ukończenie stosownego kursu. Niestety, pod znakiem zapytania pozostaje kwestia prowadzenia przez rolników wykonujących samodzielnie zabiegi zwalczania, monitoringu parametrów fumigacji, a co za tym idzie wyposażenia i stosowania specjalistycznego sprzętu. Zabiegi fumigacji najczęściej wykonywane były interwencyjnie po stwierdzeniu szkodników w surowcu, co jest dość typowe dla warunków Polski (Ignatowicz i wsp. 2009). Zabiegi we własnym zakresie wskazano w 25 ankietach, a zlecane zewnętrznej firmie DDD w 31 ankietach.

W przypadku stosowania środków kontaktowych, w 32 ankietach podano środek zawierający pirymifos metylowy (Actellic 500 EC), a tylko w 3 przypadkach środek zawierający deltametrynę (K-Obiol 25 EC). Za wyborem pierwszego ze środków może przemawiać fakt, iż rejestracja dopuszcza stosowanie go zarówno do dezynsekcji pustych powierzchni magazynowych, jak i do bezpośredniej ochrony ziarna. Rejestracja drugiego ze środków dopuszcza stosowanie go tylko do bezpośredniej ochrony ziarna (Rejestr ś.o.r. 2013). Niestety sytuacja taka może w krótkim czasie przyspieszyć procesy selekcjonowania zwalczanych populacji szkodników w kierunku populacji odpornych. Inaczej - może to powodować przyspieszenie pojawienia się odporności wśród zwalczanych populacji szkodników.

Zabiegi fumigacji środkami fosforowodorowymi wskazano w 25 ankietach. W większości przypadków podawano preparat Quickphos 56 GE. Zabiegi fumigacji prowadzono zarówno w pustych, jak i w zapełnionych ziarnem magazynach.

W 18 ankietach podano, że do zwalczania szkodników w pustych magazynach zastosowano środki biobójcze.

Najczęściej stwierdzanymi przez ankietowanych szkodnikami w magazynowanych zbożach były: chrząszcze wołków, głównie wołka zbożowego (Sitophilus granarius L.) (w 24 lokalizacjach) i trojszyków (Tribolium spp.) (w 24 lokalizacjach), motyle mklika mącznego (Anagasta kühniella Zell.) (w 7 lokalizacjach), a także roztocze (Acarina) (w 14 lokalizacjach). Rzadziej donoszono o występowaniu: chrząszczy rozpłaszczyków (Cryptolestes spp.) (w 3 lokalizacjach), mącznika młynarka (Tenebrio 
molitor L.) (w 2 lokalizacjach) i gryzków (Psocoptera) (w 2 lokalizacjach). O występowaniu innych gatunków szkodników donoszono zwykle w pojedynczych przypadkach.

Występowanie w magazynach myszy wskazano w 2 ankietach, a szczurów tylko w jednej, co jest o tyle interesujące, że szkodniki te powszechnie stwierdzane są w magazynach zbożowych i w ich otoczeniu.

\section{Wnioski / Conclusions}

1. Na podstawie przeprowadzonej ankiety stwierdzono, że ziarno zbóż w Polsce przechowywane było w różnych obiektach magazynowych, o różnym ,wieku”, pojemności i konstrukcji, zarówno w magazynach płaskich, jak i silosach stalowych, a średni czas przechowywania wynosił od 6 do 12 miesięcy.

2. W większości magazynów prowadzono okresowo manualny pomiar temperatury i wilgotności składowanych zbóż, a tylko nieliczne magazyny zbożowe wyposażone były w urządzenia pomiarowo-kontrolne.

3. Stwierdzono, że w większości ankietowanych magazynów zbożowych prowadzony był monitoring obecności szkodników magazynowych polegający na wzrokowej lustracji pryzmy i samego ziarna. Urządzenia do monitoringu szkodników magazynowych (głównie pułapki feromonowe) stosowane były dość rzadko.

4. W magazynach zwalczanie szkodników wykonywane było we własnym zakresie (głównie środki kontaktowe) i przez zewnętrzne firmy DDD (głównie gazowanie). Prowadzono je profilaktycznie w pustych obiektach, przed sezonem magazynowym, a w zapełnionych surowcem zwykle interwencyjnie, po stwierdzeniu szkodników w ziarnie.

5. Ze środków kontaktowych najczęściej stosowany był preparat Actellic 500 EC zawierający substancję czynną - pirymifos metylowy, a ze środków gazowych preparat Quickphos 56 GE generujący fosforowodór. W niektórych $\mathrm{z}$ ankietowanych magazynów stosowane były środki biobójcze do zwalczania szkodników występujących w pustych obiektach.

6. W wyniku przeprowadzonej ankiety stwierdzono, że w magazynach zbożowych występowały różne gatunki szkodników. Wśród owadów najczęściej były to: chrząszcze wołka zbożowego (Sitophilus granarius L.) i trojszyków (Tribolium spp.) oraz motyle mklika mącznego (Anagasta kühniella Zell.). Rzadziej występowały inne gatunki owadów magazynowych. Dość często w zmagazynowanych zbożach stwierdzane były roztocze (Acarina).

7. W wyniku przeprowadzonej ankiety stwierdzono, że stan magazynów i warunki, w jakich przechowywane było ziarno zbóż w Polsce był zadowalający. Należałoby jednak podjąć kroki zmierzające do uświadomienia rolnikom i podmiotom magazynującym większej odpowiedzialności za surowiec, jaki przechowują, w kontekście bezpieczeństwa żywności.

\section{Literatura / References}

Dyrektywa 128 WE 2009. Dyrektywa Parlamentu Europejskiego i Rady 2009/128/WE z dnia 21 października 2009 r. ustanawiająca ramy wspólnotowego działania na rzecz zrównoważonego stosowania pestycydów. Dziennik Urzędowy Unii Europejskiej L 309 , Tom 52, z 24 listopada 2009: 71-86.

Gołębiowska Z., Filipek P., Krzymańska J. 1968. Szkodliwość wołka zbożowego (Sitophilus granarius L.), wołka ryżowego (Sitophilus oryzae L.) i kapturnika zbożowca (Rhizopertha dominica F.) dla ziarna pszenicy i żyta. Prace Nauk. Inst. Ochr. Roślin 10 (1): 31-56.

Ignatowicz S., Oboza S., Olejarski P. 2009. Rachunek ekonomiczny zabiegów fumigacji produktów spożywczych. [Economical account for food product fumigation]. Prog. Plant Prot./Post. Ochr. Roślin 49 (4): 1617-1621.

Loschiavo S.R., Lamba R.J. 1985. Food preferences, survival, and development of four stored-product pests (Coleoptera) on rapeseed and canola (Brassica spp.). Can. Ent. 117 (5): 575-580.

Neethirajan S., Karunakaran C., Jayas D.S., White N.D.G. 2007. Detection techniques for stored-product insects in grain. Food Control 18 (2): $157-162$.

Olejarski P. 2011. Szkodniki w przechowywanym rzepaku i przygotowanie magazynu. s. 67-90. W: „Suszenie i przechowywanie rzepaku" (J. Tys, red.). Tom V. Polskie Stowarzyszenie Producentów Oleju, Warszawa, 104 ss.

Olejarski P., Rybacki R. 2011. Szkodniki występujące w magazynowanym rzepaku. [Insect pests occuring in stored rapeseed]. Prog. Plant Prot./Post. Ochr. Roślin 51 (4): 1567-1574.

Phillips J.K., Burkholder W.E. 1984. Health hazards of insects and mites in food. p. 280-292. In: "Insect Management for Food Storage and Processing" (F.J. Baur, ed.). American Association of Cereal Chemists, St. Paul, Minnesota, 384 pp.

Rajendran S. 2002. Postharvest pest losses. p. 654-656. In: "Encyclopedia of Pest Management" (D. Pimentel, ed.). Marcel-Dekker, New York, $931 \mathrm{pp}$.

Rajendran S. 2005. Detection of insect infestation in stored foods. p. 163-232. In: "Advances in Food and Nutrition Research" (S.L. Taylor, ed.). Elsevier Inc. Lincoln, Nebrasca, USA, Volume 49, 321 pp.

Rejestr ś.o.r. 2013. Rejestr środków ochrony roślin dopuszczonych do obrotu zezwoleniem Ministra Rolnictwa i Rozwoju Wsi. Ministerstwo Rolnictwa i Rozwoju Wsi. Warszawa. http://www.bip.minrol.gov.pl/DesktopDefault.aspx?TabOrgId=647\&LangId=0, dostęp: 09.04.2013.

Rozporządzenie 1107 WE 2009. Rozporządzenie Parlamentu Europejskiego i Rady (WE) nr 1107/2009 z dnia 21 października 2009 r. dotyczące wprowadzania do obrotu środków ochrony roślin i uchylające dyrektywy Rady 79//117/EWG i 91/414/EWG. Dziennik Urzędowy Unii Europejskiej L 309 z 24.11.2009 r. Tom 52, 50 ss. 
Rozporządzenie 178 WE 2002. Rozporządzenie (WE) Nr 178/2002 Parlamentu Europejskiego i Rady z dnia 28 stycznia 2002 r. ustanawiające ogólne zasady i wymagania prawa żywnościowego, powołujące Europejski Urząd ds. bezpieczeństwa żywności oraz ustanawiające procedury w zakresie bezpieczeństwa żywności. Dziennik Urzędowy Unii Europejskiej L 31 z 01.02.2002 r. Rozdział 15, Tom 6: 463-486.

Sadowski T., Drobek L. 2007. Biologiczne zanieczyszczenie żywności alergizującymi stawonogami występującymi w środowisku człowieka. [Biological contamination of food with allergic arthropods present in the human environment]. Zdrowie Publiczne 117 (1): 9-12.

Sinha R.N. 1972. Infestibility of oilseeds, clover, and millet by stored-product insects. Can. J. Plant Sci. 52: 431-440.

Sinha R.N., Wallace A.H. 1977. Storage stability of farm-stored rapeseed and barley. Can. J. Plant Sci. 57: 351-365.

Stejskal V., Hubert J. 2006. Arthropods as sources of contaminants of stored products: an overview. p. 1074-1080. In: Proc. the 9th International Working Conference on Stored Product Protection (I. Lorini, B. Bacaltchuk, H. Beckel, D. Deckers, E. Sundfeld, J.P. dos Santos, J.D. Biagi, J.C. Celaro, L.R.D'A. Faroni, L. de O.F. Bortolini, M.R. Sartori, M.C. Elias, R.N.C. Guedes, R.G. da Fonseca, V.M. Scussel, eds). Brazil, Campinas, Săo Paulo, October 15-18 2006, Brazilian Post-harvest Association - ABRAPOS, Passo Fundo, RS, Brazil, 1359 pp.

Ustawa o ochronie roślin. 2008. Ustawa z dnia 18 grudnia 2003 r. o ochronie roślin (Tekst jednolity: Dz. U. 2008 r. Nr 133, poz. 849). 